\title{
Sistema Integrado de Gestão Esportiva: uma Ferramenta de Apoio ao Programa Talento Olímpico do Paraná
}

\author{
Alternative Title: Integrated System Of Sports Management: A Support Tool to \\ the Program Olympic Talent of Paraná
}

\author{
Robson P. Bonidia \\ Universidade Estadual de \\ Londrina \\ Departamento de \\ Computação \\ robservidor@gmail.com \\ Roberto S. do Carmo \\ Universidade Estadual de \\ Londrina \\ Departamento de \\ Computação \\ robertodocarmo@gmail.com
}

\author{
Luiz A. L. Rodrigues \\ Universidade Estadual de \\ Londrina \\ Departamento de \\ Computação \\ luiz_rodrigues17@hotmail.com
}

\author{
Jacques D. Brancher \\ Universidade Estadual de \\ Londrina \\ Departamento de \\ Computação \\ jacques@uel.br
}

\author{
Carolina Massae \\ Universidade Estadual de \\ Londrina \\ Departamento de \\ Computação \\ carolinamassae@gmail.com
}

\begin{abstract}
RESUMO
Este artigo tem como objetivo relatar o desenvolvimento de uma ferramenta de apoio a gestão esportiva do programa Talento Olímpico do Paraná, denominado SIGE-TOP (Sistema Integrado de Gestão Esportiva - Talento Olímpico do Paraná), que foi desenvolvida pela Universidade Estadual de Londrina em um trabalho conjunto do Departamento de Computação e da Secretaria de Estado do Esporte do Paraná (SEES). Esta ferramenta tem o propósito de realizar um acompanhamento e automatização das ações do programa, além de gerenciar e continuamente aprimorar as políticas, procedimentos e processos do projeto. Como resultado obteve-se uma alternativa viável para integração entre as áreas envolvidas no esporte, garantindo aos jovens acadêmicos, atletas e técnicos por meio da participação de atividades sistematizadas, a utilização do tempo de forma contributiva para o desenvolvimento de suas aptidões e o trabalho cooperativo.
\end{abstract}

\section{Palavras-Chave}

Gestão Esportiva, TOP, SIGE, Governo do Estado do Paraná

\section{ABSTRACT \\ This article aims to demonstrate the efficiency of a support tool sports management from the program Olympic Talent}

Permission to make digital or hard copies of all or part of this work for personal or classroom use is granted without fee provided that copies are not made or distributed for profit or commercial advantage and that copies bear this notice and the full citation on the first page. To copy otherwise, or republish, to post on servers or to redistribute to lists, requires prior specific permission and/or a fee.

SBSI 2017 June $5^{\text {th }}-8^{\text {th }}$, 2017, Lavras, Minas Gerais, Brazil

Copyright SBC 2017. of Paraná, denominated SIGE-TOP (Integrated System Of Sports Management - Olympic Talent of Paraná), which was developed by the State University of Londrina in a joint work of the Department of Computing of the State Department of Sport of Paraná (SEES). This tool has the purpose of performing monitoring and automation of program actions, beyond its management, and continually improve its policies, procedures and project processes. As a result it was obtained a viable alternative for integration between the areas involved in sport, guaranteeing young academics, athletes and technical through participation of systematized activities, the use of time of form contributory to the development of their skills and cooperative work.

\section{CCS Concepts}

$\bullet$ Information systems $\rightarrow$ Information systems applications; Process control systems;

\section{Keywords}

Sports Management, TOP, SIGE, Government of the State of Paraná

\section{INTRODUÇÃO}

Com o rápido desenvolvimento e melhoria da vida pública e da economia social, toda a sociedade entrou na era da informação. Inerente a esse fator, o mundo dos esportes apresentou uma sistematização do desenvolvimento esportivo a partir de políticas públicas ou privadas, que tinham como elementos centrais a captação e formação de talentos esportivos mediante sistemas de treino. Dada essa expansão, surgiu-se a necessidade de um termo conhecido como gestão esportiva [9].

A gestão do esporte ou administração esportiva é responsável pelo controle, organização e direção racional e sistemática de atividades esportivas e físicas em geral. Es- 
pecificamente, ela tem a finalidade de gerenciar atividades orientadas para competições de alto nível ou participação popular e práticas de lazer e de saúde. As definições desta área de conhecimento variam de acordo com países e continentes [17].

A Sociedade Norte-Americana define esta área como um conjunto de conhecimentos que se relacionam com a direção, liderança e organização do esporte. Considerando dimensões comportamentais, ética, comunicação, finanças, negócios em contextos sociais, legislação e preparação profissional [10, 17, $22]$.

Na prática, a administração esportiva é uma tarefa de suporte ao esporte e à Educação Física desde o século XIX na Europa e nos Estados Unidos. No Brasil, suas primeiras abordagens ocorreram no início do século XX e depois mais amplamente no final da década de 1920 e durante a década de 1930 nos meios militares, que neste período ligaram o tema em exame à organização de competições e a gestão de informações esportivas [5, 10, 17, 22].

Não menos importante, a gerência de dados esportivos começa a ser compreendida como estratégia para a gestão do esporte. A gestão da informação não é um projeto ou uma ferramenta, mas sim um processo com objetivos e benefícios definidos, como: proteger e valorizar o capital intelectual, prover informação relevante, identificar quem sabe o quê, reutilizar soluções, ganhar produtividade, melhorar o processo de inovação, reduzir os silos de informação, obter e disseminar conhecimento externo e aumentar o grau de colaboração [5].

É correto afirmar que os benefícios acima descritos podem ser alcançados mediante um sistema integrado de gestão, que se apresenta como uma solução primordial para um controle eficaz e centralizado. Nesse contexto, uma ferramenta de gestão se mostra conveniente, pois abrange unicamente em um sistema, informações de todos os setores de uma administração. Todas essas informações são agrupadas, disponibilizando oportunidades de cruzamentos de dados, que podem gerar conhecimentos relevantes e apoio na tomada de decisão. Por intermédio desta solução, o fluxo de trabalho e atuação de cada profissional é relevantemente reduzido, além de apresentar baixos custos de implementação [8].

Com base nessas atribuições, o presente artigo tem o objetivo de apresentar o desenvolvimento de um sistema integrado de gestão esportiva, que proporcione acompanhamento e automatização das ações do programa Talento Olímpico do Paraná, denominado SIGE-TOP. A pesquisa vai retratar a evolução do sistema, sua arquitetura, seus módulos, a organização da base de dados, suas etapas de uso e os resultados que a ferramenta proporcionou após sua implementação.

O artigo está organizado da seguinte forma: A Seção 2, descreve os trabalhos relacionados à gestão da informação. A Seção 3, apresenta as etapas executadas para o desenvolvimento do sistema de auxílio à gestão esportiva do programa Talento Olímpico do Paraná. Na seção 4, as considerações finais são retratadas e por fim, a seção 5, discorre sobre os trabalhos futuros.

\section{TRABALHOS RELACIONADOS}

A literatura científica está repleta de trabalhos que demonstram a importância de sistemas de gestão em várias áreas do conhecimento. Deste modo, para fundamentação do presente estudo, foram identificados trabalhos correlatos à sistemas gestores. Em comum, essas pesquisas apresen- taram que a implantação de um sistema gerenciador produz uma maior confiabilidade e confidencialidade dos dados, em que um ambiente monitorado em tempo real é estabelecido. Consequentemente, isso se converte na redução do retrabalho e dedução dos custos com o mesmo [3, 9, 12].

Dentre as pesquisas selecionadas, o autores [4] abordam o desenvolvimento de um sistema integrado para controle de custos municipais, com a finalidade de possibilitar a visualização e comparação de despesas entre escolas de um município. O autor [13] demonstrou a eficácia de um sistema de gerência de pesca compartilhada. Uma alternativa viável para a efetiva participação de governo e usuários, na administração da pesca, e como um caminho para a descentralização do gerenciamento de um pesqueiro.

Os trabalhos [18, 20, 21] apresentaram sistemas de informação para coordenação de projetos científicos baseados em simulações computacionais, ferramentas web para controle e acompanhamento de uso de medicação em ambientes de vivência assistida e fatores motivadores e inibidores que impactam a decisão de adotar um sistema de gestão para operadoras de planos de saúde.

Em uma linha de estudo similar a proposta deste artigo, os autores $[2,5,16,19]$ descreveram conceitos relativos a informação, conhecimento e gestão, relacionando as iniciativas de sistemas gerenciadores de informações esportivas. Essas pesquisas relataram que é possível afirmar que um sistema de gestão é uma estrutura comprovada para gerenciar e continuamente melhorar as políticas, procedimentos e processos de uma organização. Mediante esta estrutura é possível controlar seus riscos sociais, ambientais e financeiros, melhorar a eficácia operacional e promover inovação [3, 9].

\section{SISTEMA INTEGRADO DE GESTÃO ES- PORTIVA (SIGE-TOP)}

Tendo em vista as contribuições que um sistema de gestão pode exercer, como exposto na seção anterior, e a necessidade de suporte para as funções de planejamento, organização, direção e controle do programa Talento Olímpico do Paraná, formou-se uma equipe interdisciplinar de docentes e discentes de cursos de graduação e pós-graduação, do departamento de Computação da Universidade Estadual de Londrina, em um trabalho conjunto com a Secretaria de Estado do Esporte do Paraná (SEES). Considerando-se o objetivo de desenvolver um sistema integrado de gestão esportiva, para automatizar e apoiar as ações do programa.

\subsection{PROGRAMA TALENTO OLÍMPICO DO PARANÁ (TOP)}

O programa Talento Olímpico do Paraná é uma iniciativa do Governo do Estado do Paraná por meio da Secretaria de Estado do Esporte e do Turismo. Foi implementado em 2011, com a finalidade de incentivar e distribuir oportunidades aos atletas e técnicos paranaenses que desejam construir e se dedicar a carreira esportiva de forma efetiva por meio de bolsa. Este programa oferece auxílio financeiro para atletas, paratletas e técnicos [6,7].

O eixo que conceitua o Programa Talento Olímpico do Paraná é o da oportunidade de revelar atletas que tenham a intenção de construir uma carreira esportiva, preocupação que surge da necessidade não somente de identificar, mas de oportunizar e permitir ao talento esportivo que se dedique mais efetivamente à sua modalidade e carreira esportiva, por 
meio do oferecimento de bolsa, com base em critérios de desempenho técnico.

O programa é executado com recursos oriundos do próprio Governo do Estado, de patrocínios diretos e incentivos fiscais autorizados pelo Ministério do Esporte por meio da Lei de Incentivo ao Esporte. Para aproveitar ao máximo os bolsistas, são oferecidas atividades preparatórias aos mesmos, como avaliações fisiológicas e morfológicas. O TOP abrange 34 modalidades e é dividido em 7 categorias: Escolar, Formador, Nacional, Internacional, Técnico, Técnico formador e Olimpo [6, 7]. Os principais objetivos do TOP são:

i) Motivar os atletas e técnicos por meio de oferecimento de bolsa;

ii) Identificar e desenvolver potenciais talentos para as Olimpíadas e Paralimpíadas;

iii) Tornar o Paraná referência no esporte olímpico e paralímpico;

iv) Valorizar talentos esportivos e minimizar as possibilidades de evasão dos atletas paranaenses para outros centros;

v) Analisar e medir o desempenho dos atletas e técnicos em competições por meio de avaliações;

vi) Acompanhar o desenvolvimento dos atletas em treinos, competições e contribuir para o desenvolvimento social.

\subsection{EVOLUÇÃO DO PROJETO}

O projeto foi desenvolvido em 4 fases:

1. Primeira Fase (2012): Construção de uma plataforma web para cadastro e inclusão de relatórios de atividades, para atletas e técnicos;

2. Segunda Fase (2013): Módulo administrativo para selecionar os candidatos e efetuar a geração dos contratos;

3. Terceira Fase (2014): Submódulos para o sistema gerencial, como: controle financeiro, controle de relatórios de atividades cadastradas pelos bolsistas e geração de gráficos;

4. Quarta Fase (2015): Foi realizado um processo de refatoração do sistema, aplicando mudanças no design da aplicação sem modificar o seu comportamento original, assim, melhorando qualidades não-funcionais do software.

Para o desenvolvimento do sistema gestor, foram utilizadas diversas tecnologias de código aberto que serão apresentadas na próxima seção.

\subsection{ARQUITETURA}

Para o projeto de arquitetura do SIGE-TOP, foi adotado um modelo que se baseou no trabalho [11]. Esse modelo divide o sistema em três camadas: apresentação, aplicação e dados. Essa arquitetura é ilustrada na Figura 1.

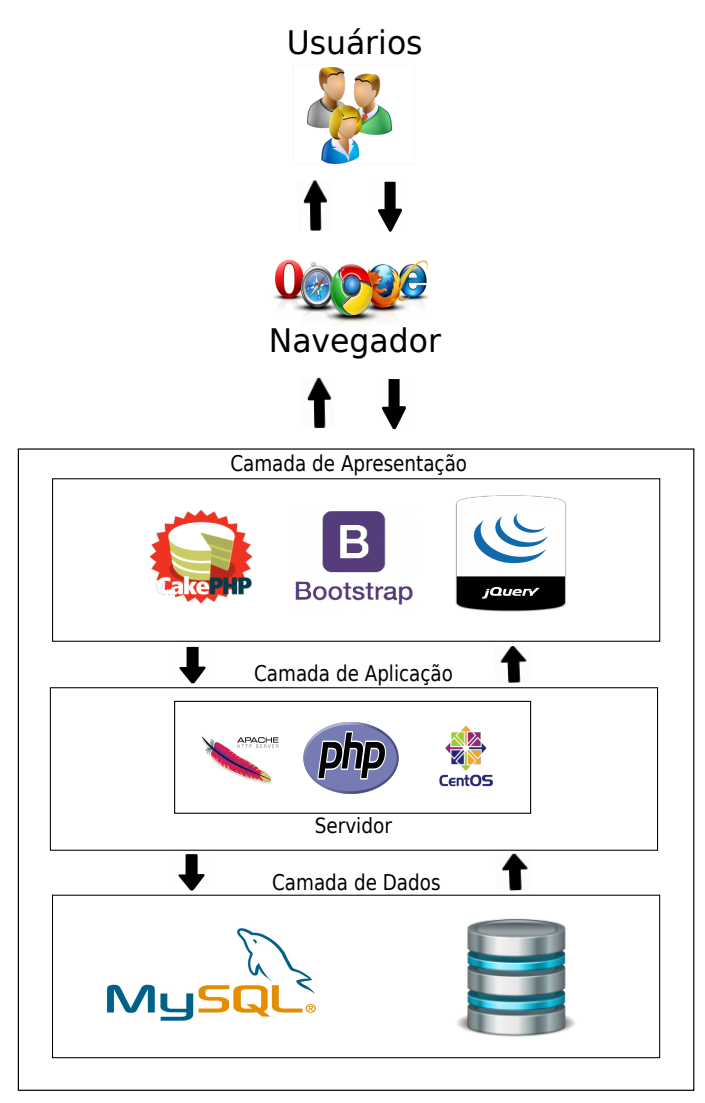

Figure 1: Arquitetura do sistema proposto

A camada de apresentação contém os elementos exibidos ao usuário final e permite a interação com o sistema. A versão web foi desenvolvida através do Framework CakePHP, Framework bootstrap e Framework jQuery. A camada de aplicação é responsável pelo processamento das operações requisitadas pelos usuários e contém toda a lógica do sistema desenvolvido através da linguagem de programação PHP. Por fim, a camada de dados é responsável por armazenar todos os dados gerados e processados pela camada de aplicação e que são visualizados na camada de apresentação. Para gerenciamento do banco de dados foi utilizado um sistema de código aberto conhecido como $M y S Q L$.

\subsection{MÓDULOS DO SISTEMA}

O sistema é composto por alguns módulos principais que estão divididos em:

- Cadastro: Este módulo é responsável pelo cadastro dos atletas e técnicos do programa. Mediante ele, é possível inserir dados pessoais e acompanhar a situação cadastral (aberta, fechada, homologada). Foi desenvolvido de modo a ser configurável, sendo possível definir o período no qual os atletas e técnicos podem efetuar cadastros;

- Controle de documentos: Módulo responsável por gerar a documentação;

- Relatórios: Módulo pelo qual os atletas e técnicos reportam as atividades; 
- Administração: Módulo em nível macro, disponível somente para os integrantes da Secretaria de Esporte e Turismo, dos Núcleos Regionais de Educação e das Federações. Ele pode ser dividido em diferentes submódulos, sendo eles: Gerenciamento de documentos, relatórios, controle financeiro, cadastro, pendências, seleção, visualização, homologação, mala direta, exportação de dados, controle de senhas e mapas.

\subsection{ETAPAS DE USO}

Iniciada às inscrições do programa Talento Olímpico do Paraná, o sistema gestor fornece a primeira etapa de cadastro. Os interessados em participar do programa fazem a criação de um usuário, o cadastro de dados básicos e confirmação de participação. Os inscritos são separados pelo sistema em 7 categorias:

1. TOP Formador: Atletas com idade entre 11 e 14 anos que estejam estudando em escolas públicas e participem de competições escolares em esportes Olímpicos e Paralímpicos;

2. TOP Escolar: Atletas com idade entre 11 e 18 anos (modalidade Olímpica) e 11 a 21 anos (modalidade Paralímpica), matriculados no ensino público ou privado com resultados expressivos em competições estaduais, nacionais ou internacionais;

3. TOP Nacional: Atletas com reconhecimento nacional e resultados expressivos em competições dentro e fora do Estado;

4. TOP Internacional: Atletas que tenham defendido o Brasil em competições internacionais e mantenham vínculo federativo no estado do Paraná;

5. TOP Olimpo: Atletas que tenham participado da última edição dos Jogos Olímpicos ou Paralímpicos e que estejam vinculados a respectiva Federação Esportiva no Estado do Paraná;

6. TOP Técnico: Estejam residindo e treinando atletas ou equipes em esportes Olímpicos ou Paralímpicos no Estado do Paraná;

7. TOP Técnico Formador: Residindo e treinando atletas ou equipes que participam de competições escolares, devendo estar vinculados a Estabelecimentos de Ensino da Rede Estadual do Paraná.

Após o término das inscrições, o sistema libera uma nova etapa para os coordenadores dos Núcleos Regionais de Educação e das Federações esportivas selecionarem os bolsistas. Uma vez selecionados, os bolsistas devem gerar os contratos no SIGE-TOP e enviá-los assinados para a Secretaria de Esporte e Turismo (SEET). Em seguida, com os contratos em mãos, a SEET em Curitiba valida as inscrições e homologa as bolsas. Por fim, os bolsistas selecionados e inscritos, devem preencher relatórios de rendimento no sistema, informando detalhes dos treinos, do local e também como a bolsa está sendo investida. Todas as etapas acima expostas, são controladas automaticamente pelo sistema através de variáveis de início e fim.

\subsection{MÓDULO ADMINISTRATIVO}

O maior módulo do sistema é o Administrativo, que é composto por vários submódulos. Entre eles estão:

- Mala Direta: Responsável pelo envio de e-mails de aviso geral da equipe do SEET. Neste submódulo, podese filtrar o envio de e-mails para os Núcleos Regionais de Educação, Federações e também categorias de bolsistas. Sempre que um e-mail é enviado, uma cópia oculta é repassada para o correio eletrônico oficial do programa, com o objetivo de garantir a entrega dos e-mails enviados;

- Visualização: É possível realizar uma série de filtros dos bolsistas cadastrados, envolvendo Cidade, Nome, $\mathrm{CPF}$, entre outros atributos;

- Seleção: Página de seleção dos candidatos a bolsa e visualização dos já selecionados. Atua como um acompanhamento do trabalho dos Núcleos Regionais de Educação e Federações por parte do SEET;

- Pendências: Permite aos gestores, cadastrar novas pendências de documentos com aviso automático para os bolsistas. Esse mecanismo agiliza o processo de validação de cadastro. Anteriormente, esse método era feito somente via correspondências, o que aumentava consideravelmente o tempo para homologação;

- Homologação: Utilizado pelo SEET para homologar as bolsas e bolsistas;

- Controle de Relatórios: Permite verificar a quantidade e a periodicidade em que os bolsistas estão fazendo o preenchimento dos relatórios de rendimento;

- Pagamentos: Controle dos pagamentos de bolsa que já foram feitos. Nesse submódulo, pode-se verificar se o atleta já preencheu os relatórios (pré-requisito básico para recebimento de bolsa);

- Exportação de Dados: Geração de relatórios em formato $C S V, X l s x$ e $X M L$;

- Cadastrar Bolsistas: Neste submódulo um administrador pode cadastrar um novo candidato a bolsa mesmo fora do período hábil;

- Alterar senha: Gerar novas senhas para bolsistas;

- Mapa: Responsável por anexar informações de cadastro em um mapa interativo. Onde é possível verificar a quantidade de bolsistas por cidade, além de informações básicas do IBGE, como população e área;

- Gráficos: Concede aos administradores a permissão para gerar gráficos distintos de resultados obtidos por bolsistas do programa.

\subsection{ORGANIZAÇÃO DO BANCO DE DADOS}

Um bom sistema de banco de dados deve apresentar um projeto, que visa a organização das informações, para que o futuro software obtenha boa performance e também facilite as manutenções que venham a acontecer $[1,15]$.

Baseado nessas afirmações, o projeto SIGE-TOP elaborou um esquema lógico de uma base de dados. A Tabela 1, exemplifica o esquema e apresenta o tipo de dado armazenado em cada relação do banco. 
Table 1: Organização do Banco de Dados

\begin{tabular}{|c|c|c|c|}
\hline Tabela & Descrição & Tabela & Descrição \\
\hline Usuários & $\begin{array}{l}\text { Credenciais dos usuários do sistema. } \\
\text { Os usuário são divididos em grupos, } \\
\text { de acordo com seu papel dentro do sis- } \\
\text { tema. }\end{array}$ & Grupos & $\begin{array}{l}\text { Armazena as opções de grupos } \\
\text { disponíveis no sistema. }\end{array}$ \\
\hline Categorias & $\begin{array}{l}\text { Armazena as categorias existentes no } \\
\text { TOP (TOP Formador, TOP Escolar, } \\
\text { TOP técnico formador, etc). }\end{array}$ & Federações & $\begin{array}{l}\text { Informações das federações esporti- } \\
\text { vas. }\end{array}$ \\
\hline Modalidades & $\begin{array}{l}\text { Informações das modalidades esporti- } \\
\text { vas. Cada modalidade é relacionada a } \\
\text { uma federação responsável. }\end{array}$ & Nres & $\begin{array}{l}\text { Contém as informações dos Núcleos } \\
\text { Regionais de Educação. }\end{array}$ \\
\hline Escolas & $\begin{array}{l}\text { Informação sobre as escolas do } \\
\text { Paraná. Cada escola é relacionada ao } \\
\text { Núcleo Regional de Educação. }\end{array}$ & Seed & Informações do SEED. \\
\hline Municípios & $\begin{array}{l}\text { Armazena o nome de todos os municí- } \\
\text { pios do Paraná. }\end{array}$ & Pessoas & $\begin{array}{l}\text { Informações básicas das pessoas } \\
\text { cadastradas no sistema. }\end{array}$ \\
\hline Atletas & $\begin{array}{l}\text { Informações dos bolsistas que se } \\
\text { cadastraram nas categorias que per- } \\
\text { tencem aos atletas. }\end{array}$ & Técnicos & $\begin{array}{l}\text { Informações dos bolsistas que se } \\
\text { cadastraram nas categorias que per- } \\
\text { tencem aos técnicos. }\end{array}$ \\
\hline Atletas_mod & $\begin{array}{l}\text { Relação que armazena as modalidades } \\
\text { dos atletas. }\end{array}$ & Técnicos_mod & $\begin{array}{l}\text { Relação que armazena as modalidades } \\
\text { dos técnicos. }\end{array}$ \\
\hline Eventos & $\begin{array}{l}\text { Contém as informações dos eventos } \\
\text { que os bolsistas participaram, como: } \\
\text { nome, data e local. }\end{array}$ & Imagens & $\begin{array}{l}\text { Os bolsistas cadastram as imagens } \\
\text { do evento, para a administrativo ter } \\
\text { acesso. }\end{array}$ \\
\hline Colocações & $\begin{array}{l}\text { Contém as informações das colocações } \\
\text { que um atleta conseguiu em um deter- } \\
\text { minado evento. }\end{array}$ & Provas & $\begin{array}{l}\text { Informações dos diferentes tipos de } \\
\text { provas dentro de cada modalidade. }\end{array}$ \\
\hline Lesões & $\begin{array}{l}\text { Contém dados das lesões dos bolsis- } \\
\text { tas. }\end{array}$ & Interrupções & $\begin{array}{l}\text { Dados de interrupção por não lesão } \\
\text { dos bolsistas. Problemas familiares, } \\
\text { escolares, entre outros. }\end{array}$ \\
\hline Relatórios & $\begin{array}{l}\text { Relatórios dos bolsistas sobre a dedi- } \\
\text { cação ao esporte. }\end{array}$ & Avaliações & $\begin{array}{l}\text { Dados das avaliações feitas nos bol- } \\
\text { sista antes, durante ou ao fim do pro- } \\
\text { cesso de bolsa. }\end{array}$ \\
\hline Relat_gastos & Gastos dos bolsistas com a bolsa. & Contratos & Código do contrato. \\
\hline Pendências & $\begin{array}{l}\text { Informações dos documentos que pre- } \\
\text { cisam ser entregues para SEED. }\end{array}$ & Homologados & $\begin{array}{l}\text { Contém as informações extras dos bol- } \\
\text { sistas homologados. Como tamanho } \\
\text { do boné, camiseta, agasalho e conta } \\
\text { bancária para receber a bolsa. }\end{array}$ \\
\hline Pagamentos & $\begin{array}{l}\text { Contém as dados dos pagamentos das } \\
\text { bolsas por bolsista. }\end{array}$ & Mapas & $\begin{array}{l}\text { Informações de IBGE para apresen- } \\
\text { tação do mapa estático. }\end{array}$ \\
\hline
\end{tabular}

Após o término do projeto lógico, ele foi transposto para um banco de dados físico. Essa implementação proporcionou ao programa Talento Olímpico do Paraná o controle centralizado de seus dados e uma atualização e recuperação de informações mais rápida e eficiente.

\subsection{APRESENTAÇÃO DO SISTEMA E RE- SULTADOS TANGÍVEIS}

Até o momento o SIGE-TOP abrange o cadastro dos atletas e técnicos do Estado do Paraná, o controle de documentos, a inclusão e geração de relatórios por parte dos atletas, técnicos e administradores. Além do gerenciamento geral do sistema pelos Núcleos Regionais de Ensino, Federações e integrantes da Secretaria de Esporte e Turismo do Paraná. A Figura 2 apresenta a página inicial do sistema.

A página inicial apresenta informações e instruções para os usuários sobre o programa TOP, prazos de entrega de documentos, relatórios, atalhos para as principais funções da ferramenta e um módulo de ajuda. Esse módulo do sistema possui uma página chamada Fale Conosco, que seria um canal de atendimento aos usuários. Essa função permite que os usuários enviem dúvidas, sugestões ou problemas encontrados ao utilizar a ferramenta de forma geral. As requisições são enviadas diretamente para o e-mail de suporte técnico.

O sistema é utilizado por 3276 usuários bolsistas (atletas e técnicos), em conjunto com os gestores do sistema, como ilustrado na Figura 3. De acordo com o gráfico, 1025 usuários são da categoria TOP escolar, 394 do TOP nacional, 38 do TOP olimpo, 1561 do TOP formador, 85 do TOP técnico e 173 do TOP técnico formador.

No módulo administrativo, a ferramenta é utilizado por 32 Núcleos Regionais de Educação, que apresentam 1474 escolas cadastradas no sistema, sendo 883 estaduais, 21 federais, 162 municipais e 408 privadas. Integrantes da secretaria estadual de esporte e turismo e 37 federações do Es- 


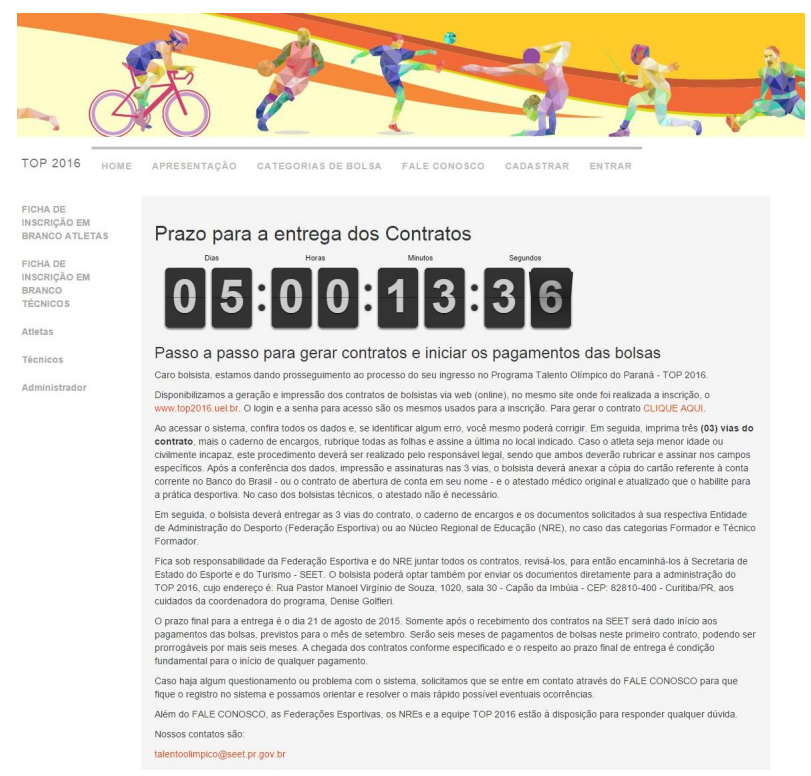

Figure 2: Página Inicial SIGE-TOP

tado do Paraná também desfrutam da ferramenta. Dentre a Federações estão: Basketball, Ginástica, Voleibol, Taekwondo, Ciclismo, Atletismo, Tênis, Tiro Esportivo, Golfe, Judô, Remo, Futebol, entre outras. É adequado dizer que o sistema apresenta uma grande quantidade de acessos simultâneos.

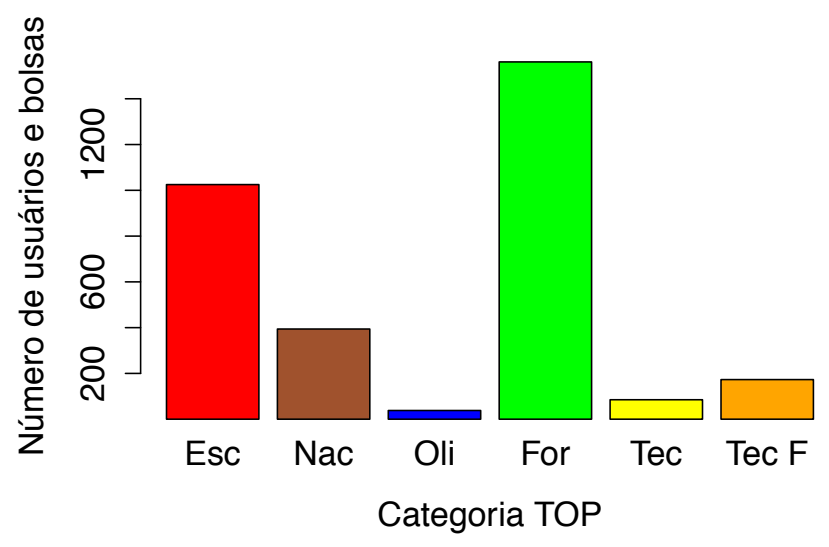

Figure 3: Quantidade de usuários

Como destacado no início do artigo, o SIGE-TOP possui usuários intitulados como administradores gerais, onde possuem uma página específica, como ilustrado na Figura 4. Mediante essa página, é possível administrar, consultar e homologar inscrições e cadastros de atletas e técnicos. Visualizar e controlar os relatórios de bolsistas. Enviar emails por mala direta, desenvolver questionários, gerenciar informações financeiras, gerar gráficos e solicitar ajuda, entre outras funções básicas de um sistema gestor.
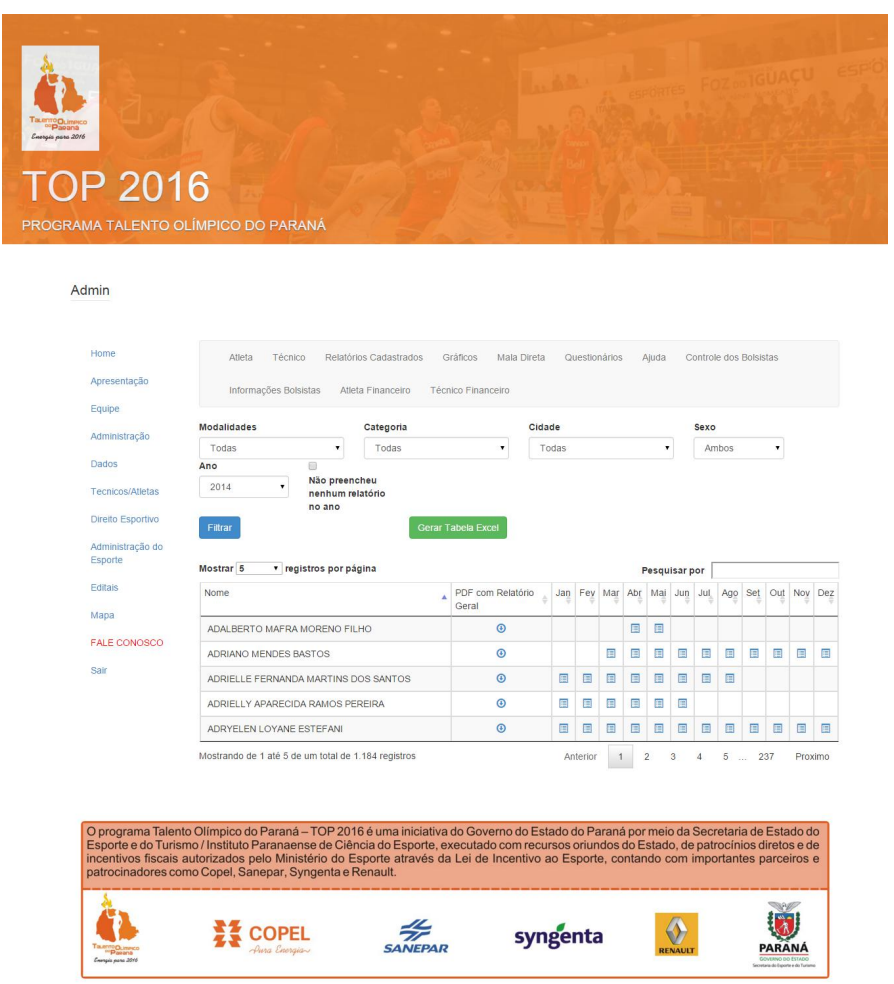

Figure 4: Página administradores SIGE-TOP

A figura 4, acima, apresenta a página administrativa do sistema, especificamente, o submódulo para controle de relatório dos bolsistas. Responsável pela gerência da inclusão de atividades e resultados de atletas e técnicos. Os relatórios anexados ao sistema, relatam 7633 eventos cadastrados de acordo com a Figura 5. No qual, 723 eventos são municipais, 3034 estaduais, 2377 nacionais, 983 internacionais e 516 olímpicos. São 60 modalidades esportivas incluídas nos relatórios de eventos, sendo 38 olímpicas e 22 paralímpicas.

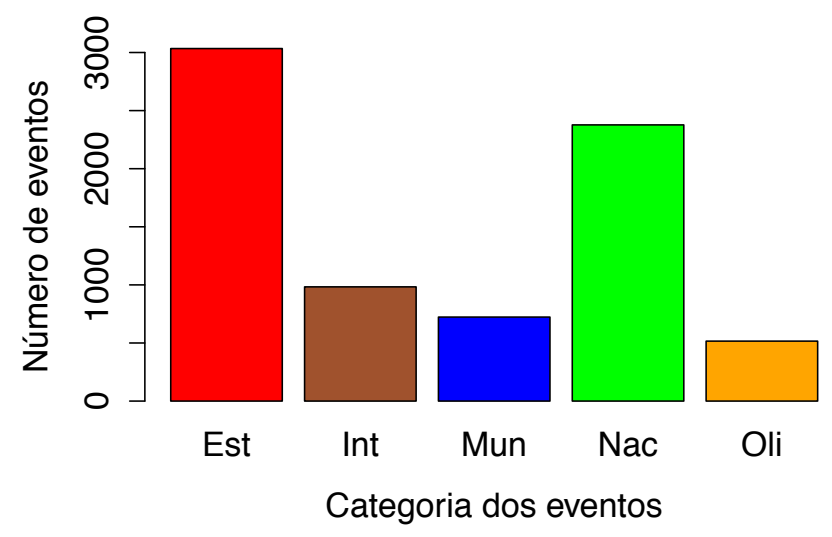

Figure 5: Eventos Cadastrados no SIGE-TOP

Por fim, a Figura 6 exemplifica o submódulo gerencial, responsável por anexar informações de cadastro em um mapa interativo. 

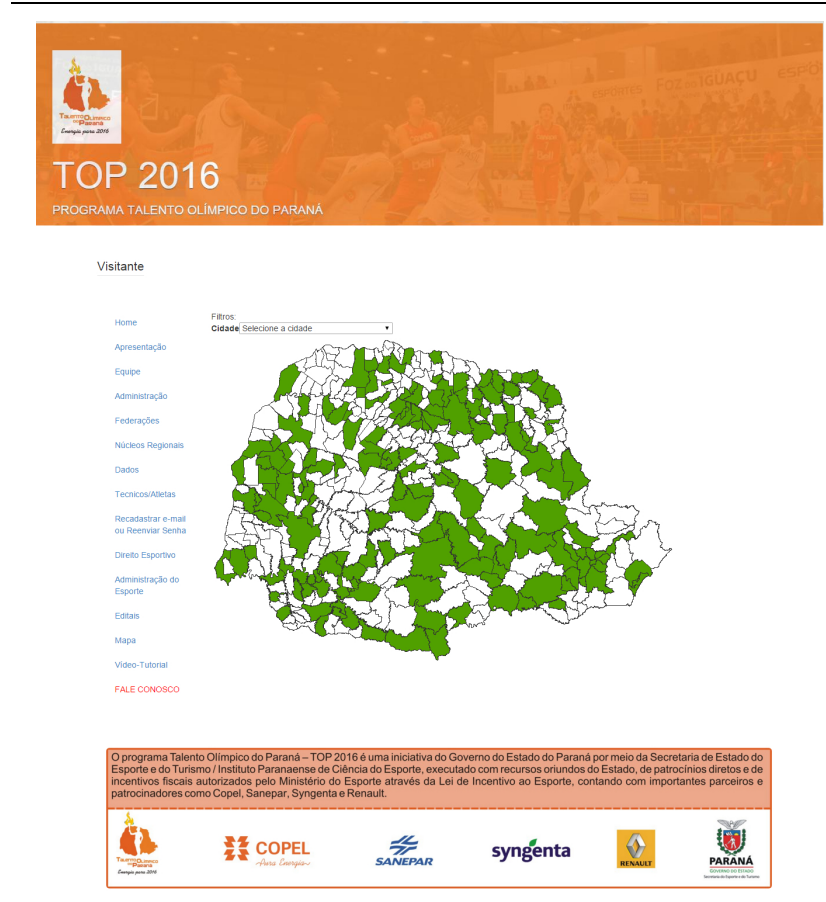

Figure 6: Página mapa interativo SIGE-TOP

Por intermédio dessa página, é possível verificar a quantidade de bolsistas por cidade, além de dados básicos do IBGE, como população e área.

Com base nas atribuições retratadas nesta subseção e como evidenciado, apresentado e relatado neste artigo, o SIGETOP está executando seu propósito que é coletar, armazenar e distribuir informações autênticas do programa TOP, com a finalidade de apoiar funções organizacionais e proporcionar integração, coordenação, controle, análise, acompanhamento, comunicação e visualização do ambiente de trabalho, transformando dados em informações úteis para tomada de decisões [14].

Todavia, o sistema ainda prossegue seu desenvolvimento, consequentemente, novos módulos estão sendo projetados com objetivo de aplicar continuamente melhorias na ferramenta. Além das novas funções, o sistema vai passar por uma nova refatoração, com a finalidade de melhorar a estrutura interna e externa do código, sem alterar seu comportamento atual.

\section{CONSIDERAÇÕES FINAIS}

O presente artigo relatou o desenvolvimento de um sistema integrado para gestão esportiva do programa Talento Olímpico do Paraná, responsável por incentivar e distribuir oportunidades aos atletas e técnicos paranaenses que desejam construir e se dedicar a carreira esportiva de forma efetiva por meio de oferecimento de bolsa. A ferramenta foi desenvolvida com base nos trabalhos $[2,4,5,12,13,16,18$, $19,20,21]$, que demonstraram a importância de sistemas gestores em diversas áreas do conhecimento.

O sistema denominado SIGE-TOP foi desenvolvido pela Universidade Estadual de Londrina em um trabalho conjunto do Departamento de Computação e da Secretaria de Estado do Esporte do Paraná. A ferramenta tem como finalidade realizar o acompanhamento e automatização das ações do programa TOP. Por meio desse artigo, foi possível conhecer a evolução do sistema, sua arquitetura, seus módulos, a organização do projeto da base de dados e suas etapas de uso.

Pode-se concluir, que através da ferramenta desenvolvida, os gestores esportivos poderão ter uma visão mais ampla e fidedigna das ações realizadas no programa. Além de uma alternativa viável para integração entre as áreas envolvidas no esporte, garantindo aos jovens acadêmicos, atletas e técnicos por meio da participação de atividades sistematizadas, a utilização do tempo de forma contributiva para o desenvolvimento de suas aptidões e o trabalho cooperativo.

\section{TRABALHOS FUTUROS}

Com os resultados obtidos na realização deste trabalho, assim como o conhecimento adquirido no desenvolvimento do estudo, pretende-se desenvolver um sistema integrado ao SIGE-TOP, para gestão de eventos desportivos.

\section{AGRADECIMENTOS}

Este trabalho teve apoio financeiro da Secretaria do Esporte e do Turismo do Estado do Paraná.

\section{REFERENCES}

[1] S. Abiteboul, R. Hull, and V. Vianu. Foundations of databases: the logical level. Addison-Wesley Longman Publishing Co., Inc., 1995.

[2] A. F. Albuquerque. Gestão estratégica das informações internas na pequena empresa. $\mathrm{PhD}$ thesis, Universidade de São Paulo, 2004.

[3] N. Arantes. Sistemas de gestão empresarial. São Paulo: Atlas, 1998.

[4] A. P. Avila-Santos, D. S. Kaster, E. Baccarin, L. F. Negreiros, and S. F. A. Vieira. Sistema integrado de custo municipal: uma ferramenta de apoio à tomada de decisão pelo gestor público. XI Simpósio Brasileiro de Sistemas de Informação, pages 651-658, 2015.

[5] M. A. Botelho, A. M. Monteiro, and V. Valls. A gestão do conhecimento esportivo: a experiência da biblioteca da seme. Ciência e Informação, Brasília, 36(1):175-188, 2007.

[6] R. Busto, A. J. Achour, J. Brancher, R. Souza, and A. C. Gomes. Iniciação e aperfeiçoamento ao esporte paralímpico. 2014.

[7] R. Busto, A. J. Achour, A. C. Dourado, J. Brancher, M. Zernei, and S. Vieira. Apoio às diversas ações definidas no projeto talento olímpico do paraná-top 2016. 2014.

[8] E. Carravetta. Modernização da gestão no futebol brasileiro. Editora AGE Ltda, 2006.

[9] F. da Cunha Bastos. Administração esportiva: área de estudo, pesquisa e perspectivas no brasil. Motrivivência, (20-21):295-306, 2003.

[10] C. M. da ROCHA and F. da Cunha Bastos. Gestão do esporte: definindo a área. Revista Brasileira de Educação Física e Esporte, 25(spe):91-103, 2011.

[11] L. H. de Andrade, B. d. S. P. Amorim, M. G. de Oliveira, A. L. F. Alves, J. N. L. de Abrante, D. F. B. Leite, J. H. Rocha, and C. de Souza Baptista. Deuzikachico: o poder da agi no monitoramento e combate de epidemias como a de dengue, zika e 
chikungunya. XII Simpósio Brasileiro de Sistemas de Informação, pages 377-384, 2016.

[12] L. F. de Carvalho, E. A. Carazza, D. B. F. Carvalho, F. Corrêa, and A. de Falco Brasileiro.

Desenvolvimento de guia eletrônico na forma de aplicativo móvel: Uma abordagem para a semana santa de são joão del-rei-mg. XII Simpósio Brasileiro de Sistemas de Informação, pages 361-368, 2016.

[13] D. C. KaliKosKi et al. Gestão compartilhada e comunitária da pesca no brasil: avanços e desafios. Ambiente ES Sociedade, 12(1):151-172, 2009.

[14] K. C. LAUDON and J. P. LAUDON. Sistemas de informação gerenciais: administrando a empresa digital. tradução arlete simille marques, 2004.

[15] C. Y. Matsumoto. A importância do banco de dados em uma organização. Maringá Management: Revista de Ciências Empresariais: on-line, 3(1), 2006.

[16] V. Mocsányi and F. da Cunha Bastos. Gestão de pessoas na administração esportiva: considerações sobre os principais processos. Revista Mackenzie de Educação Física e Esporte, 4(4), 2009.

[17] V. P. NOLASCO, V. BITENCOURT, P. B. PAOLI, E. GOMES, and M. CASTRO. Administração/gestão esportiva. Atlas do esporte no Brasil. Rio de Janeiro: CONFEF, 2006.

[18] L. S. Ramos, K. A. Ocaña, and D. de Oliveira. Um sistema de informação para gerência de projetos científicos baseados em simulações computacionais. XII Simpósio Brasileiro de Sistemas de Informação, pages 216-223, 2016.

[19] E. W. Ritter and S. J. Rigo. Fitdata: Um sistema para monitoramento de atividade física baseado em dispositivos móveis. XII Simpósio Brasileiro de Sistemas de Informação, pages 550-557, 2016.

[20] M. V. T. Sucupira. Caracteristicas de utilizacao de software as a service: Um estudo sobre as operadoras de planos de saude. Projetos e Dissertações em Sistemas de Informação e Gestão do Conhecimento, 4(1), 2015.

[21] M. S. Teixeira, L. O. Freitas, J. S. Gubiani, and U. H. Schiefelbein. Sistema web para gerenciamento e acompanhamento de uso de medicação em ambientes de vivência assistida. XII Simpósio Brasileiro de Sistemas de Informação, pages 278-284, 2016.

[22] H. Xu. The research sports management monitoring system based on wsn. International Journal of Multimedia and Ubiquitous Engineering, 10(12):79-88, 2015 . 